\title{
Tempos de escola: narrativas da formação discente ao ofício docente
}

\author{
Aline Oliveira Vieira* \\ Wagner dos Santos ${ }^{* *}$ \\ Amarílio Ferreira Neto***
}

\begin{abstract}
Resumo: Este estudo teve como objetivo dar visibilidade aos espaços formativos identificados por professores de Educação Física do ensino médio da rede estadual do Espírito Santo, como significativos em suas histórias e práticas profissionais. Usa, como referencial teórico-metodológico, as narrativas (auto)biográficas, em um movimento compartilhado de pesquisa. Os professores identificam como espaços formadores: as experiências sociocorporais vivenciadas inicialmente e/ou ampliadas nos tempos de graduação, as aprendizagens trocadas nos diálogos com colegas e professores da graduação, em momentos extraclasse, e a participação em cursos de extensão universitária e estágios. Palavras Chave: Narrativa. Espaços formativos. Educação física. Ensino médio.
\end{abstract}

\section{INTRODUÇÃo}

O trabalho com narrativas na abordagem biográfica e (auto)biográfica foi se constituindo em um crescente emprego metodológico nos últimos 20 anos, no cenário da Educação. Embalados por leituras e apropriações, principalmente europeias, de autores como Antônio Nóvoa, Mathias Finger, Christine Josso, Gaston Pineau, Pierre Dominice e Delory-Monberguer, os estudos que

\footnotetext{
'Programa de Pós-Graduação em Educação Física. Universidade Federal do Espírito Santo. Pesquisadora do Instituto de Pesquisa em Educação e Educação Física (PROTEORIA), Vitória, ES, Brasil. e-mail: ninna.maguinhos@gmail.com

"Programa de Pós-Graduação em Educação Física. Universidade Federal do Espírito Santo. Pesquisador do Instituto de Pesquisa em Educação e Educação Física (PROTEORIA), Vitória, ES, Brasil. e-mail: wagnercefd@gmail.com

"*'Programa de Pós-Graduação em Educação Física. Universidade Federal do Espírito Santo. Pesquisador do Instituto de Pesquisa em Educação e Educação Física (PROTEORIA), Vitória, ES, Brasil.e-mail: amarilio@proteoria.org
} 
assumem essa perspectiva procuram compreender a formação como um complexo processo de interação teoria e prática, no desenvolvimento da capacidade de pesquisa pelo docente e em suas tomadas de decisões em situações dinâmicas da vida nas escolas.

Apesar do crescente interesse dessa abordagem pela Educação, a pesquisa narrrativa se apresenta de forma tímida na produção teórica da Educação Física (WITTIZORECKI et al., 2006; VIEIRA, 2011). Para Wittizorecki et al. (2006), esse tipo de pesquisa se faz necessário por protagonizar uma inovação metodológica e, ao mesmo tempo, possibilitar a produção de conhecimento por meio de processos (auto)formativos docentes no contexto da Educação Física.

De igual modo, notamos uma carência de estudos na Educação Física que tratam das práticas de formação docente no ensino médio, uma vez que os trabalhos focalizam o ensino fundamental (VIEIRA, $2011)^{1}$. Nesta pesquisa, objetivamos dar visibilidade, por meio das narrativas (auto)biográficas, aos lugares/espaços identificados pelos professores de Educação Física do ensino médio da rede estadual do Espírito Santo, como significativos em suas histórias de formação, mesmo antes da escolha da profissão até sua atuação docente.

Os resíduos da experiência dos docentes ganham nas narrativas formas de linguagem que redefinem modos de ser e viver, revisitando histórias nas memórias-fragmentos (PEREZ, 2003), retalhos de uma vida que se escolhe para lembrar. No narrar o mundo cotidiano criado na experiência e recriado na rememoração, buscamos um fazer história que rompa com a linearidade do espaço e tempo, entrelaçando passado, presente e futuro no agora. Desse modo, as narrativas configuram-se como um meio para aproximarmos diferentes tempos e espaços formativos e nos implicam ao comprometimento com os objetivos de cada instância institucional, a partir das relações de parceria e colaboração que se estabelecem entre universidade e escola.

\footnotetext{
${ }^{1} \mathrm{Em}$ um mapeamento sobre a temática formação de professores e pesquisa narrativa, no período de 2000 a 2010, Vieira (2011) encontra dezessete estudos: doze nos anais dos Conbrace e cinco na RBCE. Desses, doze foram no ensino fundamental, dois no ensino fundamental/ médio e na educação infantil e um no ensino superior.
} 


\section{Caminhos teórico-metodológicos}

A abordagem teórico-metodológica se constituiu em uma leitura de práticas formativas docentes, dedicando-se a observar tanto lugares como espaços formadores. Para Certeau (1994, p. 24), os lugares são entendidos como

[...] uma ordem segundo a qual se distribuem elementos nas relações de coexistência. Ali se acha, portanto, excluída a possibilidade para duas coisas ocuparem o mesmo lugar. Impera-se a lei do próprio: os elementos considerados se acham uns ao lado do outro cada um situado num lugar próprio e distinto que define. [...] é, portanto, a configuração instantânea de posições, e isso implica uma indicação de estabilidade.

Com esse intuito, interessa-nos observar como esses lugares são ocupados e apropriados pelos docentes, transformando-se em espaços que, de acordo com Certeau (1994, p. 201), são "[...] produzidos pelas operações que os orientam, os circunstanciam, os temporalizam e os levam a funcionar em unidades polivalentes de programas conflituais ou de proximidades contratuais. Em suma, o espaço é um lugar praticado".

Esse agir dos professores produz espaços, contextos de circunstâncias de um fazer particular, entendidos como entrelugares de formação, que não se configurariam pelos lugares instituídos. Ferraço (2005, p. 37) salienta a necessidade de dedicarmos nossa atenção às ações docentes que

[...] praticam currículos e processos de formação continuada que não se deixam aprisionar todo tempo por identidades culturais ou políticas, originais ou fixas, que ameaçam, em alguns momentos, o discurso oficial de uma proposta única para todo sistema, abrindo brechas que desafiam o instituído.

A busca pelos entrelugares de formação foi necessária para compreendermos os usos (CERTEAU, 1994) que os docentes fizeram com o que lhes foi oferecido, como subversores das 
estratégias das instituições, transformando, por meio das maneiras de fazer, lugares em espaços praticados. Nessa direção, a pesquisa dá visibilidade para o percurso de formação discente ao ofício docente de Educação Física da Superintendência Regional de Carapina, da rede estadual de ensino do Espírito Santo. Assim, mergulhamos não somente nos momentos formadores institucionais, mas, sobretudo, nos espaços praticados nos processos autoformativos discentes/docentes. Entendemos como espaços autoforamtivos os

[...] processos próprios de reflexão do fazer cotidiano, portanto, espaços privilegiados de produção curricular e, sobretudo, espaço de formação. Formas criativas e particulares pelas quais professoras e professores buscam o aprendizado de seus alunos, e avançam muito além daquilo que poderíamos compreender, via textos de propostas de cursos. [...] processos de interação cotidianos com outros colegas e nos diálogos estabelecidos com estes. Aprendizagens mais ou menos não formais no contato com a produção acadêmica e na busca por cursos (OLIVEIRA, 2005, p. 46).

Os docentes assumiram o papel de narradores de suas práticas, fazendo o que Benjamin (1994) nos alerta, uma escrita que a história hegemônica teima em calar: a das narrativas de histórias cotidianas. Dessa maneira, a arte de narrar foi assumida como:

[...] Uma forma artesanal de comunicação. Ela não está interessada em transmitir o 'puro em si' da coisa narrada como uma informação ou um relatório. Ela mergulha a coisa na vida do narrador para em seguida retirá-la dele. Assim se imprime na narrativa a marca do narrador, como a mão do oleiro na argila do vaso (BENJAMIN, 1994, p. 205).

Nesse contexto, a narrativa foi compreendida como as experiências passadas de uma pessoa para outra, em um processo de trocas de vivências, emoções e sensações. Ao mergulharmos nas narrativas dos docentes em seus percursos de formação, 
aproximamo-nos do resgate das experiências singulares e coletivas, rememoradas e compartilhadas pelos professores colaboradores do estudo.

Assim, a história que a pesquisa se propôs a visibilizar, por meio das narrativas, trouxe na colaboração dos docentes suas memórias, compreendidas como ruínas (BENJAMIN, 1994) que devem ser revisitadas no presente, no sentido de organizar a narrativa em um movimento de reminiscência, entendida como "[...] uma cadeia de acontecimentos encarnada pelo narrador; ela tece uma rede de histórias comum entre si. Em cada uma delas vive uma Sherazade, que cria uma nova história, aquela que está se contando" (BENJAMIN, 1994, p. 205).

No presente, o narrador, a partir de uma atividade mimética (BENJAMIN, 1994), selecionou o que lembrar, delineando uma ação de produzir uma imagem dos acontecidos. Nesse sentido, a narrativa docente trouxe a intencionalidade do narrador ao produzir uma interpretação das práticas no presente daquilo que ele escolhe para rememorar. A narrativa (auto)biográfica foi tecida ao longo dos encontros com seis docentes ${ }^{2}$. Foram considerados como fonte a narrativa oral e todo o material imagético (ALVES, 2007) selecionado pelos docentes. A narrativa (auto)biográfica foi realizada a partir da temática formação e prática docente. Todo material transcrito foi apresentado aos docentes, organizado e sistematizado com eles, mediante também os outros materiais de imagem.

A Regional de Carapina foi escolhida pela facilidade de acesso e acompanhamento dos espaços/lugares de formação, já que a pesquisadora é docente concursada nessa regional, e ainda pelo interesse dos professores em participar do estudo.

Os seis docentes colaboradores do estudo possuíam vínculo efetivo, com exercício de sala de aula em escolas regulares, e frequentaram alguns momentos de formação contínua oferecidos

${ }^{2}$ Os docentes colaboradores concederam o uso da gravação e divulgação da narrativa, assinando o Termo de Livre Consentimento, previsto pelo Comitê de Ética da Universidade Federal do Espírito Santo. O projeto do estudo foi aprovado pelo comitê, tendo como número de protocolo $118 ? 11$. 
pela Secretaria Estadual de Educação, nos anos de 2009-2010. Com o objetivo de atender ao projeto "Esporte na Escola", em 2009, a Secretaria ofertou uma capacitação/atualização docente. No entanto, em algumas reuniões da Superintendência de Carapina, os docentes sentiram necessidade de potencializar aqueles momentos coletivos de reflexões para além da perspectiva dos "jogos na rede", trazendo relatos de experiência de diferentes níveis de ensino - séries iniciais e finais do ensino fundamental, ensino médio, educação de jovens e adultos e educação inclusiva. Paralelamente a essas ações, houve em 2009/2010 a iniciativa de um Programa de Formação Continuada em Educação Física Escolar, no intuito de discutir e implementar o Currículo Básico Comum elaborado pela Secretaria Estadual de Educação ${ }^{3}$.

\section{OS NARRADORES: DE PROFESSOR PARA PROFESSOR}

Benjamin (2006) traz uma maneira de escrita de histórias como a prática de um colecionador que reúne documentos, imagens, textos, sem preocupação com uma ordem cronológica, fazendo da desordem das ideias um panorama diferenciado de produção para a sua época. Entendemos que o grande aprendizado que o autor nos incita seria direcionar nossos olhares a compreender as relações humanas nas complexas ações cotidianas, sem uma necessidade inicial de organizálas de maneira linear, observando o tempo acontecido. Nesse instante, aproximamo-nos de Certeau (1994), que nos ajudou a analisar as maneiras de fazer e dizer o cotidiano social por escritas ordinárias que seus praticantes produzem, uma inventividade rotineira que gera histórias de um hoje que, em um instante, vira ontem e decai nas ruínas da memória.

\footnotetext{
${ }^{3}$ Esse Programa compreendia em um trabalho com onze Secretarias Regionais Estaduais, com turmas de 15 a 45 professores da área. Contou com atividades presenciais e não-presenciais, totalizando 320 horas. O tema central do Programa foi o Currículo Básico Comum e tinha por objetivo instrumentalizar os professores para o trabalho nas escolas Estaduais, a fim de garantir práticas que partissem da orientação dessa diretriz curricular.
} 
No baú de suas memórias, os docentes elencaram recortes de um tempo para ser lembrado. Esses recortes foram por nós organizados como em um trabalho de um colecionador: agrupar momentos raros, interligar pistas e indícios (GINZBURG, 1989) de narrativas que transversalizavam a mesma temática e indicavam o mesmo cenário do acontecido. São espaços próprios (CERTEAU, 2006) que cada professor ocupa e deles narraram suas trajetórias, selecionando o que foi significativo e se tornou marcas de experiência no magistério, conforme Figura 1.

Figura 1 - Os docentes narradores: um baú de histórias da Educação Física na rede estadual de ensino do Espírito Santo

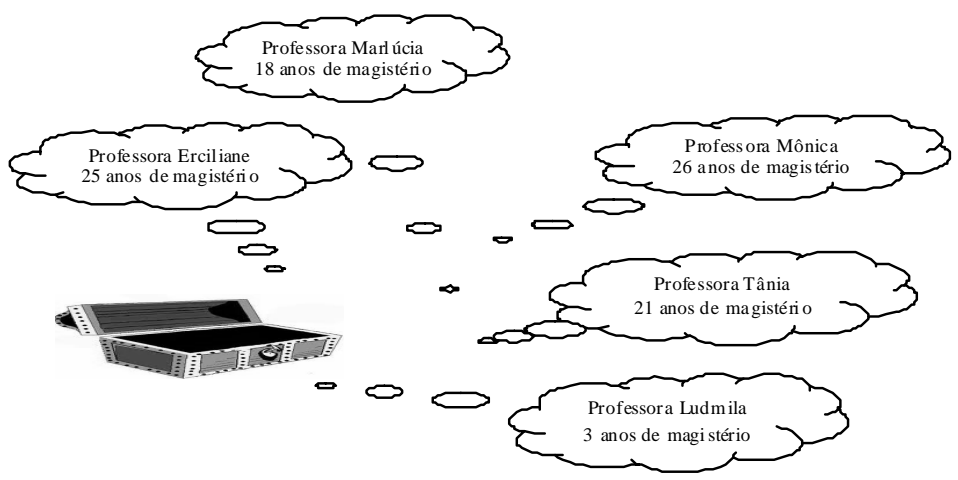

Ao falarmos da escolha da profissão docente e de como nos constituímos professores(as), autores como Nóvoa e Finger (1988), Josso (2004), Fontana (2010), Catani (1997), Souza (2008, 2010) e Figueiredo $(2004,2008)$ têm mostrado como as experiências escolares, nos tempos vividos de educação básica como discentes, influenciam a opção pela carreira do magistério.

As narrativas (auto)biográficas dos docentes desta pesquisa sinalizam como os primeiros contatos com professores de Educação 
Física, em sua formação de educação básica, são decisivos para a construção de suas primeiras concepções de ação pedagógica ${ }^{4}$. Essa referência constituiu-se para alguns pela via da admiração pela pessoa-professor e também pelos conteúdos vivenciados na Educação Física Escolar. Para outros, pela via da frustração no sentido de "ser o profissional que eu não tive na escola", como podemos ler nas narrativas das professoras Marilúcia e Ludmila:

Sempre gostei muito de Educação Física. Você vê como a escola influencia. Eu adorava as aulas de Educação Física, meus professores. Brincava muito nas aulas. Minha turma de ginásio era quase um time. Seguimos juntos da quinta à oitava série. Então, jogamos, competindo pela escola, vôlei e handebol. Era muito gostoso todo aquele clima de jurar a Bandeira, cada escola levar uma dança, receber as medalhas. É por isso a escolha da Educação Física (PROFESSORA MARILÚCIA, outubro, 2010).

A escolha pela Educação Física foi por estar presente em minha vida desde a infância. Começou pela natação, depois veio o ballet e a ginástica olímpica, isso tudo em Minas Gerais. Porém, na escola, nas aulas de Educação Física, tanto no fundamental como no médio, eu sofria muita exclusão, pois era péssima nos esportes com bola e não havia opção de outra atividade para mim. Ficava frustrada na escola porque pensava: 'Poxa, mais será que as aulas de Educação Física é só isso, bola?'. Por isso, quando decidi lecionar em escola, pensava em fazer diferente, ser uma professora diferente para as outras pessoas que são iguais a mim (PROFESSORA LUDMILA, outubro, 2010).

As narrativas remetem, pela rememoração, à possibilidade do encontro entre gerações, entre história e memória, principalmente da infância e dos tempos de escola. Ao escavar suas reminiscências (BENJAMIN, 1994), as professoras revelaram passagens que

${ }^{4}$ Figueiredo $(2004,2008)$ apresenta-nos o modo como as experiências sociocorporais dos alunos vivenciadas anteriormente à formação em Educação Física, no ensino fundamental e médio, influenciam na escolha pelo curso, bem como na valorização de determinados conteúdos curriculares durante a formação inicial. 
apontam desejos e possibilidades de encontro entre passado e presente de uma Educação Física que permanece na forma com que o adulto-professor constitui suas ações, sua maneira peculiar de se relacionar e agir pessoal-profissionalmente com a área.

A professora Ludmila traz as imagens da infância nas experiências sociocorporais (FIGUEIREDO, 2008) que a motivavam e, por conseguinte, trouxeram reflexões ao contexto da escola, no sentido de não compreender por que na Educação Física Escolar só tem bola e não, também, aquelas atividades que lhe davam prazer. A narrativa de Ludmila nos remete ainda a um problema com o qual a nossa área tem se deparado, qual seja, a definição "do que ensinar" e "quando ensinar". De um lado, observamos a não diversificação dos conteúdos de ensino mediante o predomínio das modalidades esportivas handebol, voleibol, basquete e futsal ${ }^{5}$. De outro, verificamos uma repetição do que é ensinado nos diferentes anos de escolarização, sem um aumento de sua complexidade ou diversificação que leve em consideração o quando e por que ensinar.

Schneider e Bueno (2005) demonstram, por exemplo, que os alunos das séries/anos finais do ensino fundamental dão pouco valor à Educação Física, já os das séries iniciais desse segmento estabelecem uma leitura positiva. Ao que parece, o ensino do conteúdo esporte, nas primeiras séries/anos de escolarização do ensino fundamental, apresenta-se como novo e interessante para os alunos e, na medida em que vão avançando no processo de escolarização, esses conteúdos se tornam repetitivos, provocando desinteresse.

Contudo, as narrativas de Mônica e Erciliane demonstram como as experiências fora das escolas contribuíram na escolha profissional.

[...] o que me levou a ser professora de Educação Física foi ter sido atleta de ginástica olímpica. Além disso, tem o meu amor pela dança (PROFESSORA MÔNICA, outubro, 2010).

\footnotetext{
${ }^{5}$ Ver trabalhos de Souza e Marchi Júnior (2011) e de Faria (2004).
} 
[...] A dança me acompanha desde a infância e isso foi fundamental e determinante para embarcar nessa de ser professora (PROFESSORA ERCILIANE, outubro, 2010).

Ao falar das imagens da infância, Benjamin (1994) nos ajuda a compreender como as experiências que vivenciamos nessa época da vida trazem ao presente profundas marcas que advogam nas escolhas e nos nossos projetos profissionais. Percebemos, no cruzamento das narrativas de Erciliane, Mônica e Ludmila, que as diferentes experiências vivenciadas com as práticas sociocorporais e, em especial, com a dança, fora e no contexto escolar, foram marcantes para a escolha profissional e para a atuação pedagógica com esse conteúdo de ensino.

Nas escavações que trazem a proximidade com os tempos de juventude, o professor Altamiro fez o mergulho na melancolia dos tempos difíceis entre a revelação do eu-pessoal e a formação do euprofissional.

Eu não consigo lembrar sem me emocionar. Não me arrependo de ter me formado professor de Educação Física. Meu pai era analfabeto, minha mãe morreu muito cedo, quando eu tinha 11 anos. Antes de eu fazer faculdade, tinha um curso que era chamado insuficiência. Então, eu podia dar aula. Naquela época, a Educação Física era uma área muito carente de profissional. Paguei a faculdade via crédito educativo. Nossas disciplinas eram teóricas e práticas. Tinha o professor muito famoso, o Darcymires Rêgo, de ginástica artística, que lançou livros. Eu estudei com um dos maiores professores de Biologia: Claúdio Gil. Ele ensinava da seguinte forma: tudo ele perguntava: 'Por quê?'. Então, dessa maneira questionadora, ele me ensinou muito (ALTAMIRO, novembro, 2010).

Pela narrativa do professor Altamiro, compreendemos como um processo de rememoração pessoal tece a memória individual, social e coletiva de um contexto histórico (PEREZ, 2006). As fotografias selecionadas por ele oferecem pistas (GINZBURG, 1989) daquilo que, para o docente, permanece vivo em sua memória, por 
ter sido uma experiência prazerosa das práticas educativas e formativas de Educação Física nos tempos de graduação. Foram resgates de momentos de aula, amizades e colegas de profissão, momentos de congressos da área que circunscreveram reminiscências (BENJAMIN, 1994) exteriorizadas ao longo da prática educativa desse professor pelas redes de ensino pelas quais passou.

Identificamos, como espaços e movimentos autoformativos, as partilhas, vivências e debates, tanto com professores das disciplinas, quanto com os colegas de faculdade. Esses espaços praticados foram rememorados por Altamiro, Marlúcia, Mônica e Erciliane com ênfase nas práticas esportivas que demarcaram suas experiências. $\mathrm{O}$ aprender, dessa maneira, requer uma relação com o saber que se constitui na/pela experiência. Bondiá (2001, p. 21), ao entender a experiência como algo "[...] que nos passa, que nos acontece, que nos toca", sublinha a singularidade e subjetividade de sua vivência, assim como o saber que dela emerge "[...] é um saber que não pode separar-se do indivíduo concreto em quem encarna" (BONDÍA, 2001, p. 27).

Nessa perspectiva, Bondía (2001, p. 27) define que o saber da experiência "[...] se adquire no modo como alguém vai respondendo ao que lhe vai acontecendo ao longo da vida e no modo como vamos dando sentido ao acontecer do que nos acontece". A experiência e o saber que dela derivam são, na verdade, para Bondiá (2001), o que nos permite apropriar-nos de nossa própria vida. Tratar, desse modo, do saber da experiência faz-se necessário considerar a experiência de cada um, pois esse saber não está "[...] fora de nós, mas somente tem sentido no modo como configura uma personalidade, um caráter, uma sensibilidade ou, em definitivo, uma forma humana singular de estar no mundo, que é por sua vez uma ética (um modo de conduzirse) e uma estética (um estilo)" (BONDÍA, 2001, p. 27).

A relação que os professores estabelecem com o saber é demarcada pelos modos como dão sentido e significado às experiências que lhes aconteceram antes/durante a formação inicial. 
Para Charlot (2000, p. 78-79),

[...] a relação com o saber é relação com o tempo. A apropriação do mundo, a construção de si mesmo, a inscrição em uma rede de relações com os outros - 'o aprender' - requerem tempo e jamais acabam. [...] Esse tempo, por fim, se desenvolve em três dimensões, que se interpenetram e se supõem uma à outra: o presente, o passado, o futuro.

As narrativas compartilhadas até o momento evidenciam a relação epistêmica com o saber em diferentes tempos e espaços de formação pelos professores. As experiências sociocorporais vivenciadas na escola e em outros lugares formativos foram decisivas para as escolhas da profissão e da atuação profissional. Observamos a força dos saberes privilegiados pela Educação Física, que se "[...] projetam por meio do domínio de uma atividade, no caso atividades que demandam controle e uso do corpo e de movimento" (SCHNEIDER; BUENO, 2005, p. 39).

O aprendizado conferido pela/na Educação Física, com base na relação com o saber, tem como estatuto privilegiado o domínio de uma atividade e o saber do qual se apropria na relação com o outro e consigo, quando comparados aos saberes que são incorporados aos objetos ${ }^{6}$. Segundo Charlot (2009), o objetivo fundamental de uma educação que se pretende física, que visa ao corpo, é o próprio corpo, ou seja, a apropriação de regras e reflexividade valem quando elas oferecem suporte a práticas incorporadas no corpo, fato esse apresentado pelos professores. Assim,

Os conhecimentos com os quais a disciplina Educação Física lida, como os esportes, jogos, danças, lutas e ginástica, são atividades constantemente submetidas a minivariações de situações de aplicação, por isso a dificuldade de

\footnotetext{
${ }^{6}$ Ao estabelecer um inventário sobre as figuras do aprender, Charlot $(2000$, p. 66) constrói as seguintes classificações: "[...] objetos-saberes, objetos nos quais os saberes estão incorporados [...]; objetos cujo uso deve ser aprendido [...]; atividades a serem dominadas, as quais possuem estatutos variados [...]; e, dispositivos relacionais, os quais só podem ser apropriados na relação com o outro". Essas figuras podem ser resumidas em três: "[...] constituição de um universo de saberes-objetos, ação no mundo, regulação da relação com os outros e consigo" (CHARLOT, 2000, p. 71).
} 
expô-las integralmente em forma de enunciados. Fazer com, nesse sentido, indica o tipo de investigação que se pode desenvolver quando se busca compreender o conhecimento que os alunos e alunas conseguiram mais incorporar do que sistematizar em forma de enunciados [...] (SCHNEIDER; BUENO, 2005, p. 40).

As narrativas indicam como as experiências sociocorporais se constituem pelo fazer com nas aulas de Educação Física e demarcam as formações dos professores. Questão esta destacada no processo de rememoração dos tempos de universidade. Em uma mescla de nostalgia e orgulho por ter tido uma formação mais "prática" do que "teórica" no Centro de Educação Física e Desportos (CEFD) da Universidade Federal do Espírito Santo (Ufes), as professoras Mônica e Erciliane, formadas na década de 1980, revelam:

Eu entrei na Ufes em 1979. Nessa época, tinha um currículo bem agradável. As disciplinas tinham a dinâmica de ser prática e teórica. Tínhamos que ir às escolas fazer algum tipo de trabalho final. Nos dividíamos em grupos e lá, na educação básica, montávamos festivais, torneios ou simplesmente aulas. No entanto, a maioria dos professores da universidade nos via como atletas e acabavam dando aula na forma de treinamento, e não nos ensinando como ser professores. Hoje não vejo que isso seja tão relevante, pois não somos técnicos esportivos, somos educadores. Das disciplinas a que mais me marcou foi a de Didática, porque a professora que lecionou nos deu base para saber como deveríamos planejar uma aula (PROFESSORA MÔNICA, novembro, 2010).

Eu me formei na Ufes em 1984. Na época, era um curso de muitas disciplinas práticas. Agente saía da piscina, ia para ginástica olímpica, tudo correndo, éramos como atletas. Como o que me levou a escolher o curso foi a dança, tinha a professora Conceição como uma fonte de saber. Eu também tinha paixão pela ginástica rítmica, não deixando a professora Marzi em paz. No final do curso, entrou o professor Paulo Roberto, com aquelas ideias renovadoras e toda polêmica das sucatas e latarias. Nossa turma gostou muito da 
proposta dele que era da psicomotricidade (PROFESSORA ERCILIANE, novembro, 2010).

As narrativas das docentes trazem ênfase no vivido das práticas curriculares de suas graduações. O contexto delineado enfatiza experiências que não desapareceram da história do sujeito em formação. No presente, as narradoras constroem a rememoração da formação inicial no encontro com aquilo que dela foi significativo para sua prática docente na educação básica. Dessa maneira, enfatizam em suas falas dois aspectos determinantes: se, por um lado, o contexto técnico-instrumental das disciplinas foi considerado como excessivo, quando seus professores universitários cobravam uma performance assemelhando ao treinamento de atletas; por outro, destacam terem sido necessárias essas experiências para se ter "segurança" na atuação pedagógica como professoras.

Para Mônica e Erciliane, sobressaem, durante a formação inicial, a relação com o saber que se pauta pelo domínio de uma atividade, no caso, das técnicas do movimentar-se das disciplinas esportivas e da dança. Ao inscrevê-las corporalmente, as docentes carregaram esse aprendizado como experiências fundamentais para sua futura atuação na Educação Física.

Além disso, identificamos que a relação com o saber das narradoras no momento de formação inicial nos remete a três características comuns no vivido/praticado que se configuram nas figuras do aprender apresentadas por Charlot (2000): a) a relação com o saber se estabelece pelas experiências sociocorporais vivenciadas mesmo antes da graduação que, ao longo do curso superior, acabaram sendo elencadas como prioritárias no intuito de aprofundar o conhecimento daquilo já inscrito corporalmente pelos colaboradores do estudo; b) a relação com o saber amplia-se nas discussões sobre as disciplinas curriculares tidas como inovadoras. As narradoras deram ênfase a uma discussão da psicomotricidade destacando a relevância do debate para suas futuras práticas pedagógicas com a escola, dando visibilidade à apropriação do saberobjeto; e c) a relação com o saber se estabeleceu mediante o contexto 
de relação interpessoal entre professor-aluno, no sentido de veicular a admiração pela pessoa-educador ao significado de experiências formadoras marcantes para sua futura prática profissional.

Além dos aspectos vivenciados na formação inicial, os narradores destacam a relevância dos momentos de estágio e cursos de extensão, como espaços formativos significativos. A narrativa da professora Marilúcia traz aprendizados de um curso de extensão, na época de sua graduação, no contexto da promoção de saúde, que, além de ter sido enriquecedor para sua inserção inicial no campo de atuação profissional, contribuiu com os saberes ali apreendidos posteriormente para suas aulas, principalmente as de Educação Física no ensino médio, como exposto a seguir:

Quando entrei no Curso de Educação Física na Ufes, comecei a estagiar desde o segundo período. Passei pelo Sesc e Sesi. Depois do sexto período em diante, fiz o curso de extensão em Fisiologia do Exercício com o professor Luciano Rezende. Foi muito bom para tudo, pois me deu noções de saúde que até hoje uso para ensinar meus alunos, como pressão arterial e atividade física (PROFESSORA MARLÚCIA, novembro, 2010).

[...] Quando entrei, em 2003, na Faesa, eu peguei uma parte da Educação Física diferente da formação inicial de Erciliane. O currículo era muito teórico. Por exemplo, estudava o lúdico e os jogos cooperativos só nos livros em aulas expositivas. Além disso, era como se esses fossem somente aquilo que podíamos de politicamente correto desenvolver nas aulas da escola. Então acabei me frustrando bastante, pois achava que, na graduação, ia aprender a jogar bola [...]. Durante o estágio obrigatório nas escolas, criticava muito os professores da rede pública, dizendo que eles não trabalhavam direito. Hoje sou obrigada a admitir que o dia a dia não é tão simples e aí, quando vamos dar aula, é que estamos em contato com a realidade e não apenas com o aprendido na faculdade (PROFESSORA LUDMILA, novembro, 2010). 
Os recortes narrativos vislumbram dois períodos históricos de formação inicial: de um lado, a formação de Marilúcia no CEFD/ UFES no início da década de 1990, quando a formação acadêmica transversalizava o debate da atuação da Educação Física em diferentes espaços profissionais, respaldados pela Resolução CFE $n^{\circ} 03 / 1987$, tendo com isso uma formação em licenciatura plena em Educação Física. Por outro lado, temos a formação inicial de Ludmila, que destaca a ausência do fazer com nas disciplinas curriculares da graduação, principalmente aquelas relacionadas com o esporte. Além disso, identifica a dificuldade em relacionar discussões políticopedagógicas com o contexto de prática profissional no vivido com a educação básica.

Identificamos, nas práticas formativas advindas de espaços tidos como estágios e projeto de extensão, a complexa discussão da relação teoria-prática nas disciplinas curriculares da licenciatura em Educação Física. Dialogando com Locatelli (2007), sinalizamos dois aspectos que circunstanciaram as narrativas docentes: a relevância das experiências pessoais e profissionais fora do currículo prescrito na formação dos saberes do futuro professor e a necessária articulação universidade e educação básica nas discussões das disciplinas curriculares de graduação. Nesse sentido, a autora sinaliza que

[...] o distanciamento entre experiências pessoais e profissionais dos alunos dos processos formativos e as elaborações teóricas que dão suporte à formação profissional, produzem um fosso entre aquilo que é teorizado sobre a escola e seus processos de ensino, e aquilo que é possível ser da prática pedagógica, dificultando a idéia de se valorizar o trabalho docente e a produção dos saberes dos professores em correspondência com aquilo que desenvolvem em suas trajetórias de socialização profissional. [...] todo o processo formativo e as disciplinas organizadas do currículo de graduação para dar conta de formar seus profissionais, precisam apropriar-se da idéia de ter a escola básica e os saberes profissionais que nela circulam, como importante fonte para a produção de conhecimentos dos futuros profissionais. O estágio supervisionado 
não pode ser único momento para dar conta de desenvolver relações teoria-prática. Assim as demais disciplinas deixariam de cumprir seu papel na formação dos alunos com vistas a análises e reflexões críticas daquilo que vem sendo praticado na realidade educacional (LOCATELLI, 2007, p.165-166).

As narrativas (auto)biográficas desta pesquisa destacam a tímida parceria entre universidade e educação básica, o que nos sinaliza para a necessidade de uma ação colaborativa entre as instituições formativas, em que se valorizam as relações, as práticas, os saberes produzidos pelos professores do ensino superior, discentes em formação e professores da Educação Básica na produção de conhecimentos e na autoria de suas práticas. Na tentativa de significar e de ressignificar as práticas individuais e coletivas, assim como reelaborar trajetórias profissionais a partir de referências das próprias práticas e em diálogo com teorias, destacamos a valorização da prática docente e dos saberes da experiência como alternativa para se assumir uma formação que promova a construção de saberes e a autonomia profissional (LOCATELLI, 2007).

\section{Considerações finaIS}

A escuta das memórias despertadas e reinventadas na rememoração das experiências formativas tece indícios dos caminhos trilhados no movimento de tornar-se e ser professor. Nesse caso, percebemos, nas singularidades das histórias narradas pelos docentes, que o tornar-se professor forma-se ao longo da vida, nos modos com que o futuro educador experimenta o mundo, praticando diferentes cotidianos sociais, em um constante aprendizado com os outros homens com quem o mundo é compartilhado, apropriando-se de uma parte desse mundo para a construção de uma história que é, ao mesmo tempo, profundamente singular, no que tem de única, mas que escapa por toda parte.

Nesse conjunto de relações e processos que constituem um sistema de sentido, no qual se diz quem eu sou, quem é o mundo, quem são os outros (CHARLOT, 2000), os docentes constituíram 
práticas formativas. Estas, especialmente no caso dos educadores colaboradores do estudo, foram se circunscrevendo nos momentos praticados de escolarização mesmo antes da escolha do magistério, durante a graduação, estendendo-se com o ingresso na profissão e se prolongando como processo formativo cotidiano nas práticas docentes dentro e fora da escola.

No geral, identificamos que as experiências sociocorporais de Educação Física foram, muitas delas, vivenciadas inicialmente e/ou ampliadas nos tempos de graduação narrados pelos docentes. Além disso, aprendizagens trocadas nos diálogos tecidos com colegas e professores da graduação em momentos extraclasse e a participação em cursos de extensão universitária foram espaços praticados (CERTEAU, 1994), narrados pelos professores, que identificamos como instâncias (auto)formativas.

A potencialidade do trabalho com narrativas reside, dentre outros fatores, em visibilizar práticas de formação docente em que, ao colocarmos o professor como narrador, desencadeamos ações de investigação-formação por um processo autoformativo, possibilitando ao docente registrar suas múltiplas formas de fazer com a escola e, assim, reconhecer sua autoria. 


\section{School times: narratives of students formation to teachers profession \\ Abstract: Study aimed to give visibility to training} spaces, identified by high school physical education teachers of the State of Espírito Santo, as significant in their stories and professional practices. Uses, as a theoretical and methodological references, the (auto) biographical narratives, in a research sharing movement. Teachers have identified as trainning spaces: sociocorporal experiences initially experienced and / or expanded in the time of graduation, the learning in the dialogues with graduation classmates and teachers in extra-time, and participation in university extension courses and internships.

Keywords: Narration. Training spaces. Physical education. High school.

Tiempos de la escuela: narrativas de alumnos sobre la formación para el trabajo docente

Resumen: Este estudio tuvo como objetivo dar visibilidad a los espacios formativos identificados por profesores de Educación Física de enseñanza media de la red pública estadual de Espírito Santo, como significativos en sus historias y practicas profesionales. Utiliza, como referencial teórico metodológico, las narrativas (auto) biográficas, en un movimiento compartido de pesquisa. Los profesores identifican como espacios formadores: las experiencias socio corporales vivenciadas inicialmente y/o ampliadas en los tiempos de graduación, los aprendizajes cambiados en los diálogos con amigos y profesores de la graduación, en momentos extra clases, y la participación en cursos de extensión universitaria y prácticas.

Palabras clave: Narración. Espacios formativos. Educación física. Enseñanza media.

\section{REFERÊNCIAS}

ALVES, N. Dossiê: as múltiplas formas de narrar a escola. Revista Currículo sem Fronteiras, Rio de Janeiro, v. 7, n. 2, p. 5-7, 2007.

BENJAMIN, W. O narrador. In: . Obras escolhidas: magia e técnica, arte e política. 5. ed. Rio de Janeiro: Brasiliense, 1994.

Passagens. Belo Horizonte: UFMG Editora, 2006. 
BONDÍA, J. L. Notas sobre a experiência e o saber da experiência. Revista Brasileira de Educação, Campinas, n. 19, jan./abr. 2001.

CATANI, D. B. et al. História, memória e autobiografia na pesquisa educacional e na formação. In: (Org.). Docência, memória e gênero: estudos sobre formação. São Paulo: Escrituras Editora, 1997.

CERTEAU, M. A invenção do cotidiano1: artes de fazer. Petrópolis: Vozes, 1994.

A escrita da história. 2. ed. Rio de Janeiro: Forense, 2006.

CHARLOT, B. Da relação com o saber: elementos para uma teoria. Porto Alegre: Artmed, 2000.

Ensinar a educação física ou ajudar o aluno a aprender o seu corposujeito? In: DANTAS JÚNIOR, H. S.; KUHN, R.; RIBEIRO, S. D. D. Educação física, esporte e sociedade: temas emergentes. São Critóvão: Editora da UFS, 2009. v. 3, p. 231-246.

FARIA, E. L. Conteúdos da educação física escolar: reflexões sobre educação física e cultura. Revista Mineira de Educação Física, Viçosa, v. 12, n. 2, p. 124 142, 2004.

FERRAÇO, C. E. Currículo, formação continuada de professores e cotidiano escolar: fragmentos de complexidade das redes vividas. In: Cotidiano escolar, formação de professores(as) e currículo. São Paulo: Cortez, 2005.

FIGUEIREDO, Z. C. C. Experiências sociocorporais e formação docente em educação física. Movimento, Porto Alegre, v. 14, n. 1, p. 85-110, jan./abr. 2008.

Formação docente em educação física: experiências sociais e relação com o saber. Movimento, Porto Alegre, v. 10, n. 1, p. 89-111, jan./abr. 2004.

FONTANA, R. A. C. Como nos tornamos professoras? 3. ed. Belo Horizonte: Autêntica, 2010.

GINZBURG, C. Mito, emblemas e sinais: morfologia e história. São Paulo: Companhia das Letras, 1989.

JOSSO, M. C. Experiências de vida e formação. São Paulo: Cortez, 2004.

LOCATELLI, A. Saberes docentes na formação de professores de educação física: um estudo sobre práticas colaborativas entre Universidade e Escola Básica. 2007. 207 f. Dissertação (Mestrado em Educação) - Programa de Pós-Graduação em Educação, Universidade Federal do Espírito Santo, Vitória, 2007.

NÓVOA, A.; FINGER, M. Método (auto)biográfico e a formação. Lisboa: MS/ DRHS/CFAP, 1988. 
OLIVEIRA, I. B. de. Criação curricular, autoformação e formação continuada no cotidiano escolar. In: FERRAÇO, C. E. (Org.). Cotidiano escolar, formação de professores(as) e currículo. São Paulo: Cortez, 2005.

PEREZ, C. L. V. Cotidiano: história(s), memória e narrativa: uma experiência de formação continuada de professoras alfabetizadoras. In: GARCIA, R. L. (Org.). Pesquisa com o cotidiano. Petrópolis: DP\&A, 2003.

. Histórias de escola e narrativas de professoras: a experiência do GEPMC: memória e cotidiano. In: SOUZA, E. C. Autobiografias, histórias de vida e formação: pesquisa e ensino. Porto Alegre: EdiPUCRS, 2006.

SCHNEIDER, O.; BUENO, J. G. S. A relação dos alunos com saberes compartilhados nas aulas de educação física. Movimento, Porto Alegre, v. 11, n.1, p. 23-45, jan./ abr. 2005.

SOUZA, E. C. A vida com as histórias de vida: apontamentos sobre pesquisa e formação. In: PERES, E. et al. (Org.). Trajetórias e processos de ensinar e aprender: sujeitos, currículos e culturas. Porto Alegre: EdiPUCRS, 2008.

Abordagem biográfica e pesquisa educacional: convergências teóricometodológicas e práticas de formação. In: DALBEN, A. et al. (Org.). Convergências e tensões no campo da formação e do trabalho docente. Belo Horizonte: Autêntica, 2010.

SOUZA, J. de; MARCHI JÚNIOR, W. Por uma sociologia da produção científica no campo acadêmico da educação física no Brasil. Motriz, Rio Claro, v. 17, n. 2, p. 349-360, abr./jun. 2011.

WITTIZORECKI, E. S. et al. Pesquisar exige interrogar-se: a narrativa como estratégia de pesquisa e de formação do(a) pesquisador(a). Movimento, Porto Alegre, v. 12, 2006.

VIEIRA, A. Narrativas da formação docente de educação física no ensino médio da rede estadual de ensino do Espírito Santo. 2011. 275 f. Dissertação (Mestrado em Educação Física) ? Programa de Pós-Graduação em Educação Física, Universidade Federal do Espírito Santo, 2011.

Endereço para correspondência:

Aline Oliveira Vieira

Caixa Postal 9905

AGF UNIVERSITÁRIA

Rua Arthur Czartoryski 455 Loja 1

CEP.: 29060-974

Recebido em: 03.05.2012

Aprovado em: 22.05.2012 
